\title{
Numerical Simulation of Biomass Gasification in a Fluidized Bed
}

\author{
Aiping Shi ${ }^{1 \mathrm{a}}$, Yixiang Pang ${ }^{2 \mathrm{~b}}$, Guanjie $\mathrm{Xu}^{2 \mathrm{c}}$, Cheng $\mathrm{Li}^{2 \mathrm{~d}}$ \\ 1.School of Agricultural Equipment Engineering, Zhenjiang 212013, China; \\ 2. School of Energy and Power Engineering, Zhenjiang 212013, China

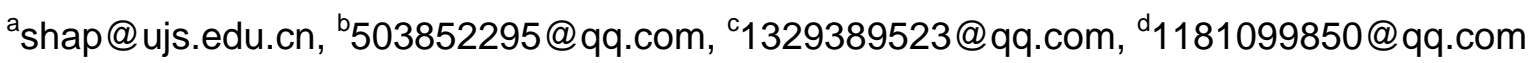

Keywords: Biomass gasification, simulation, Fluent, fluidized bed

\begin{abstract}
In order to study the effects of mass ratio of steam to biomass $\left(\mathrm{m}_{\mathrm{S}} / \mathrm{m}_{\mathrm{B}}\right)$ and temperature on the gas composition, a model was developed to simulate the biomass-steam gasification process using Fluent in a fluidized bed. The simulated results showed that the volume fraction of $\mathrm{H}_{2}$ increased firstly and then remained constant with the increase of $\mathrm{m}_{\mathrm{S}} / \mathrm{m}_{\mathrm{B}}$, and that of CO decreased firstly and then got to be stable. The results indicated that the temperature benefited biomass gasification, the volume fraction of $\mathrm{H}_{2}$ and $\mathrm{CO}$ rised. The results of simulation basically agreed with that of experiments. Therefore, the results proved that the dynamical model could be used to simulate the biomass gasification in fluidized bed.
\end{abstract}

\section{Introduction}

The development of biomass energy is a research emphasis in the field of energy utilization in the 21st century. Biomass of modern use can be divided into the following basic types: Direct combustion, pyrolysis, gasification, liquefaction and ester exchange ${ }^{[1]}$.Currently, the development and application of gasification technology research is very valuable all over the world ${ }^{[2,3]}$. Based on the minimum Gibbs free energy, many scholars simulate the process of fuel gasification using Aspen Plus ${ }^{[4,5]}$. Howeve, Aspen Plus could not reflect the flow process of reactor and the reactor structure on the influence of the gasification process. Fluent software is one of the widely used CFD software to solve the problems at the aspect of chemical reactions and flow. There are many researchers study biomass gasification technology based on Fluent software ${ }^{[6,7 \text {,and } 8]}$. In dynamic model gasifier, gasification reaction dynamic model, reaction heat and proton transfer model in the process of the gas solid two phase fluid dynamic model phase coupling. Dynamic model involves the mechanism of biomass pyrolysis and gasification, and can simulate the gasification process in different time, different position of reaction conditions, with the development of computational fluid dynamics, dynamics model will become the inevitable trend of model development.

In the presented study, a biomass fluidized bed dynamic model based on Fluent software was established to study the effect of mass ratio of steam to biomass and temperature on the gas composition. This study provides a theoretical basis for biomass gasification process.

\section{Mathematical model}

Fluent6.3 software is used to establish the model of biomass gasification in this study. Volume reaction of component transport is used to Simulate gas homogeneous reaction in the progress of gasification. Limited rate/eddy dissipation model is adopted in rate process model. Standard $k-\varepsilon$ model is adopted in turbulence model. $P 1$ radiation model is adopted in radiation heat transfer model.

\subsection{Gas-solid fluid dynamics model}

CFD modeling of biomass gasification processes describes fluid flow, heat and mass transfer and chemical reaction process.The basic equations include mass, momentum, energy, and transport 
equations components are as follows[10]:

$$
\begin{gathered}
\frac{\partial \rho}{\partial t}+\nabla(\bar{\rho} u)=S_{P} \\
\frac{\partial(\bar{\rho} u)}{\partial t}+\nabla(\rho \overline{u u})=-\nabla p+\nabla(\mu \nabla \bar{u})+S_{N} \\
\frac{\partial(\rho H)}{\partial t}+\nabla(\rho \bar{u} H)=\nabla(\lambda \nabla T)+S_{H} \\
\frac{\partial\left(\rho Y_{f}\right)}{\partial t}+\nabla\left(\rho \bar{u} Y_{f}\right)=\nabla\left(D \nabla\left(\rho Y_{f}\right)\right)+S_{Y}+R_{f}
\end{gathered}
$$

In the formula, $\rho$-Density, $\mathrm{kg} / \mathrm{m}^{3} ; t$-Time, $s ; \quad \bar{u}$-Instantaneous velocity, $\mathrm{m} / \mathrm{s} ; \mathrm{p}$-The partial pressure of the gas component, $\mathrm{Pa} ; \mu$-Fluid dynamic viscosity, $\mathrm{Pa} \cdot \mathrm{s} ; \mathrm{H}$-Fluid specific enthalpy, $J / \mathrm{kg} ; \mathrm{T}$-Temperature, $K$; $\lambda$-Thermal conductivity of the fluid, $W /(\mathrm{m} \cdot \mathrm{K}) ; Y_{f}$ —Mass fraction of components; $D$-Diffusion coefficient of components; $R_{f}$-Production rate per unit volume within the component, $\mathrm{kg} /\left(\mathrm{s} \cdot \mathrm{m}^{3}\right) ; S_{P}$-Source term, $\mathrm{kg} /\left(\mathrm{s} \cdot \mathrm{m}^{3}\right) ; S_{N}$-Source term, $N / \mathrm{m}^{3} ; S_{H}$-Source term, $J /\left(s \cdot \mathrm{m}^{3}\right) ; S_{Y}$-Source term, $\mathrm{kg} /\left(\mathrm{s} \cdot \mathrm{m}^{3}\right)$.

\subsection{Gasification reaction model}

Normally, we consider that Biomass gasification in a fluidized bed are through the following steps: (1) Biomass particles under the environment of high temperature rapid decompose and then become coke, tar and gas;(2) the second reaction occur in gaseous product; (3) the tar crack and coke gasified. Gas-solid product produced by Biomass pyrolysis took complex gas phase and solid complex reaction under the environment of high temperature in gasifier. Main consideration of chemical reaction is as follows:

$$
\begin{array}{cc}
\mathrm{C}+\mathrm{O}_{2}=\mathrm{CO}_{2} & \text { R1 } \\
\mathrm{CO}+\frac{1}{2} \mathrm{O}_{2}=\mathrm{CO}_{2} & \text { R2 } \\
\mathrm{CH}_{4}+2 \mathrm{O}_{2}=\mathrm{CO}_{2}+2 \mathrm{H}_{2} \mathrm{O} & \mathrm{R} 3 \\
\mathrm{CO}_{2}+\mathrm{H}_{2}=\mathrm{CO}+\mathrm{H}_{2} \mathrm{O} & \mathrm{R} 4 \\
2 \mathrm{H}_{2}+\mathrm{O}_{2}=2 \mathrm{H}_{2} \mathrm{O} & \mathrm{R} 5 \\
\mathrm{C}+\mathrm{H}_{2} \mathrm{O}=\mathrm{CO}+\mathrm{H}_{2} & \text { R6 } \\
\mathrm{C}+\mathrm{CO}_{2}=2 \mathrm{CO} & \text { R7 } \\
\mathrm{CO}+\mathrm{H}_{2} \mathrm{O}=\mathrm{CO}_{2}+\mathrm{H}_{2} & \text { R8 } \\
\mathrm{CH}+\mathrm{H}_{2} \mathrm{O}=\mathrm{CO}+3 \mathrm{H}_{2} & \text { R9 }
\end{array}
$$

Model chemical reaction kinetics parameters are shown in Table 1.

In this paper, the Arrhenius model was used to define the reaction process, Arrhenius constant is obtained as follows:

$$
K_{i}=A_{i} e^{-E_{i} /(R T)}
$$

where $K_{i}$ is Arrhenius constant; $E_{i}$ is activation energy, $\mathrm{kJ} / \mathrm{mol} ; A_{i}$ is pre-exponential factor; $R$ is molar gas constant, $8.314 \mathrm{~J} /(\mathrm{mol} \cdot \mathrm{K}) ; T$ is temperature, $K$. 
Table 1 Parameters of chemical dynamics

\begin{tabular}{cccc}
\hline Reaction & Activation energy $\mathrm{E}_{\mathrm{i}}(\mathrm{J} / \mathrm{mol})$ & Pre-exponential factor $\mathrm{A}_{\mathrm{i}}(\mathrm{1} / \mathrm{s})$ & References \\
\hline R1 & 97400 & $4.8 \times 10^{3}$ & {$[9]$} \\
R2 & 99760 & $3.09 \times 10^{5}$ & {$[9]$} \\
R3 & 930400 & $2.552 \times 10^{14}$ & {$[9]$} \\
R4 & 398300 & $6.245 \times 10^{14}$ & {$[9]$} \\
R5 & 99760 & $8.83 \times 10^{8}$ & {$[9]$} \\
R6 & 232000 & $1.05 \times 10^{7}$ & {$[9]$} \\
R7 & 245000 & $1.18 \times 10^{7}$ & {$[9]$} \\
R8 & 369000 & $2.978 \times 10^{12}$ & {$[9]$} \\
R9 & 30000 & $6.9888 \times 10^{3}$ & {$[10]$} \\
\hline
\end{tabular}

\section{Calculation method}

\subsection{Model hypothesis}

Due to the fact that the gasification of biomass gasifier is very complex, We simplified model and put forward the following hypothesis:(1)Biomass is dry ash-free basis, considering only tar and volatile; (2)Volatile of biomass separate out in a moment at high temperature;(3)CO, H2, CH4, CO2, $\mathrm{H} 2 \mathrm{O}, \mathrm{N} 2$ and $\mathrm{O} 2$ are considered during the gasification process.

\subsection{Boundary conditions}

Boundary conditions of the simulation were set as, the operating pressure was $101325 \mathrm{~Pa}$, the environment temperature was $300 \mathrm{~K}$ and the gasifier export was pressure export. Gasifier wall on the infiltration is without velocity slip and quality conditions. Wall temperature is set to 500K.

\subsection{The reactor structure and grid}

Experiment equipment used is a biomass fluidized bed gasifier.Experiment system is shown in Figure 1. It is mainly composed of gasification device, feeding device, air supply device, separation and purification device and gas storage device. In this study, the diameter of the bottom of the biomass gasifier is $150 \mathrm{~mm}$, top diameter is $300 \mathrm{~mm}$ and height is $1600 \mathrm{~mm}$. In the experiment, gasification medium vapor entered the fluidized bed from the bottom. Biomass entered the fluidized bed from biomass inlet the side of the fluidized bed. Gas product discharged from the gasifier outlet at the top of the profile.In the experiment, vinegar residue was used for biomass material of the simulation study . Currently, recycle of vinegar residue is rare. Its material properties and parameters are shown in table 2.Bed material of the experiment is fluidized bed boiler slag, its average particle diameter is $4 \mathrm{~mm}$. Vinegar bad average particle size is $5 \mathrm{~mm}$.

The model adopted tetrahedron and hexahedron mesh. It had a total of 39732 mesh. Biomass gasifier simplified mesh diagram is shown in figure 2 .

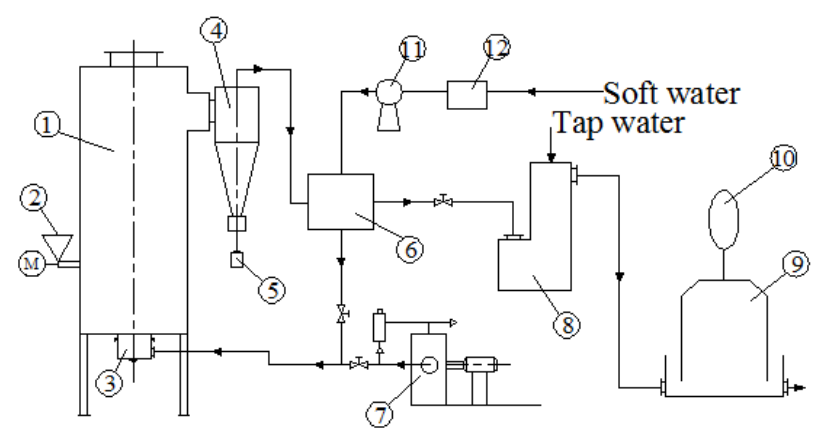

1.Biomass fluidized bed gasifer 2.Biomass hopper 3.Wind room 4.High-temperature cyclone separator 5.Char collector 6.Tube type heat exchanger 7.Roots blower 8.Wet scrubber 9.Bell type gas holder 10.Product gas collection bag 11.Soft water pump 12.Soft water tank

Fig.1 Simple system diagram of biomass fluidized bed gasification 


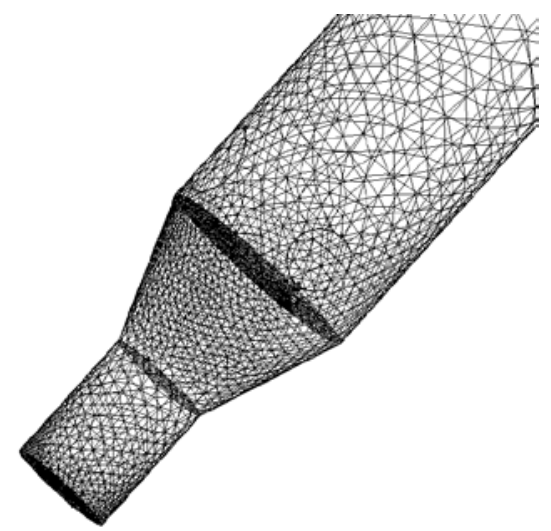

Fig.2 Mesh for biomass gasifier

Table2 Properties of vinegar residue

\begin{tabular}{|c|c|c|c|c|c|c|c|c|}
\hline \multicolumn{4}{|c|}{ Industry analysis(ad) \% } & \multicolumn{5}{|c|}{ Elemental analysis \% } \\
\hline Mad & Aad & Vad & Fcad & $\mathrm{C}$ & $\mathrm{H}$ & $\mathrm{O}$ & $\mathrm{N}$ & $\mathrm{S}$ \\
\hline 10.85 & 14.85 & 60.46 & 13.84 & 38.83 & 4.94 & 29.11 & 1.42 & 0.72 \\
\hline
\end{tabular}

\section{Calculation results and analysis}

\section{1 gas composition distribution}

Simulation of seven conditions were studied. the influence of $\mathrm{mS} / \mathrm{mB}$ and gasification temperature on biomass gasification was investigated and the simulation value with the experimental value were compared as well. Operating conditions are shown in table 3. The longitudinal section of $Y=0$ section was taken to describe the gas volume fraction. Figure 3 shows the gas volume fraction distribution of working condition 2. The volume fraction of $\mathrm{H} 2$ rised firstly and then remained constant, and that of $\mathrm{CO}$ decreased firstly and then got to be stable. Since the reaction proceeded, the temperature in the gasification furnace decreased, the content of $\mathrm{CO} 2$ increased due to reductionreactionofCO2(R7).

Table 3 Parameters for calculation with various $\mathrm{m}_{\mathrm{S}} / \mathrm{m}_{\mathrm{B}}$

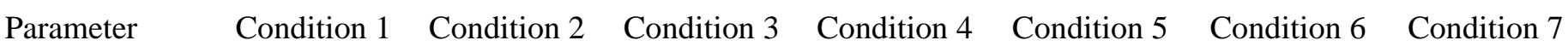

$\begin{array}{llllllll}\mathrm{m}_{\mathrm{S}} / \mathrm{m}_{\mathrm{B}} & 1.23 & 1.53 & 1.80 & 2.47 & 3.57 & 1.53 & 1.53\end{array}$

$\begin{array}{llllllll}\text { Steam }(\mathrm{kg} / \mathrm{s}) & 0.005 & 0.005 & 0.005 & 0.005 & 0.005 & 0.005 & 0.005\end{array}$

Vinegar residue addition rate $(\mathrm{kg} / \mathrm{s})$

$\begin{array}{lllllll}0.004075 & 0.003275 & 0.002775 & 0.002025 & 0.0014 & 0.003275 & 0.003275\end{array}$

Reaction
temperature $(\mathrm{K})$

1225

1225

1225

1225

1225

1175

1275 


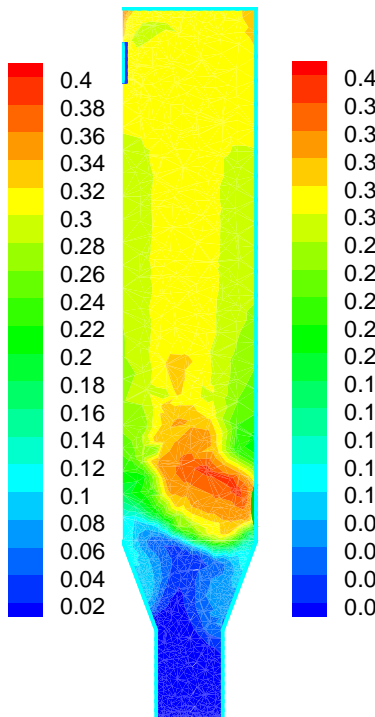

(a) $\mathrm{H}_{2}$

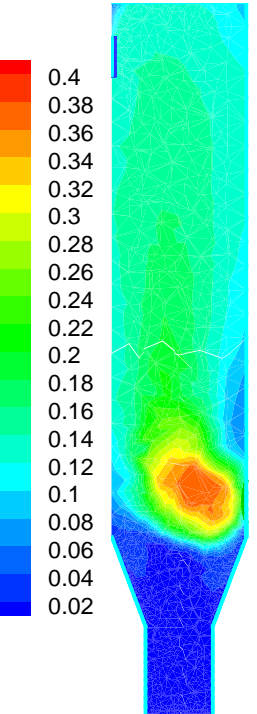

(b) $\mathrm{CO}$

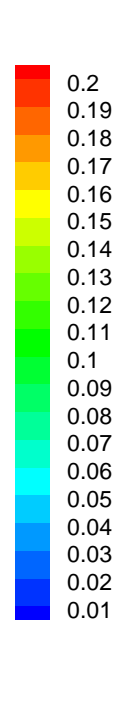

(c) $\mathrm{CO}_{2}$

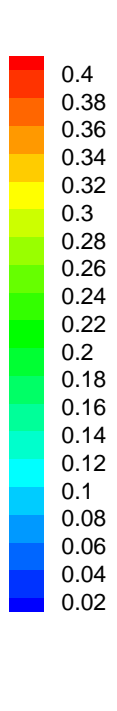

(d) $\mathrm{CH}_{4}$

Fig.3 Distribution of mole fraction of gas species in condition 2

\subsection{Influence of $\mathrm{m}_{\mathrm{S}} / \mathrm{m}_{\mathrm{B}}$ on volume fraction of gas}

Figure 4 shows the volume fraction of the gas components in the different conditions $1 \sim 5$ $(\mathrm{mS} / \mathrm{mB}=1.23 \sim 3.57)$. We compared the simulation value with the experimental value.As can be seen from simulation value in Fig. 4, the content of $\mathrm{H} 2$ gas was $40.41 \% \sim 46.67 \%$.The content of CO gas was $20.55 \% \sim 26.77 \%$.The amount of $\mathrm{CH} 4$ gas was $8.03 \% \sim 11.25 \%$. The content of $\mathrm{CO} 2$ gas was $7.76 \% \sim 10.44 \%$.The content of $(\mathrm{H} 2+\mathrm{CO})$ gas was $60.96 \% \sim 73.44 \%$.It indicates that $\mathrm{H} 2$ and $\mathrm{CO}$ gas is the most important component of the product gas.

Under the constant temperature condition, when $\mathrm{mS} / \mathrm{mB}=1.23 \sim 2.47$, water gas reaction(R6) prompted the volume fraction of $\mathrm{H} 2$ and $\mathrm{CO}$ increasing, but a small amount of water vapor water reaction with $\mathrm{CO}(\mathrm{R} 8)$ which prompted the volume fraction of $\mathrm{CO}$ decreased with the increace of $\mathrm{mS} / \mathrm{mB}$, the general trend of the volume fraction of $\mathrm{H} 2$ increased, however the volume fraction of $\mathrm{CO}$ decreased.The content of $(\mathrm{H} 2+\mathrm{CO})$ gas increased.The content of $\mathrm{CH} 4$ gas had trace increace with the increase of mass ratio of steam to biomass. It is observed that, the volume fraction of gas composition changed little since the arrival of saturated steam when $\mathrm{mS} / \mathrm{mB}$ changed from 2.47 to 3.57.. Different results between the simulation value and the experimental value in Figure 4 were due to not taking tar into account in the simulation. And as a result of the existence of tar in experiment, the tar cracked at high temperature, generated $\mathrm{CO}$ gas, therefore,the value of the $\mathrm{CO}$ in the simulation was slightly lower than that in the experiment.

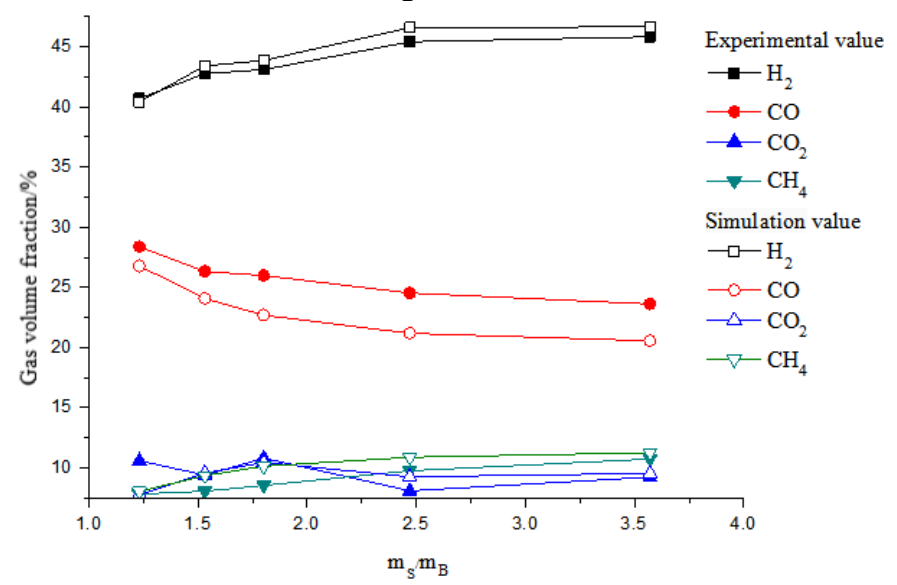

Fig.4 Effect of $\mathrm{m}_{\mathrm{S}} / \mathrm{m}_{\mathrm{B}}$ on gas component 


\subsection{Effects of temperature on volume fraction of gas}

Figure 5 shows the volume fraction of gas composition of the condition 2, 6, 7 (temperature $=$ $1175 \sim 1275 \mathrm{~K})$. the simulation value was compared with the experimental value. Within the scope of the fluidized bed gasification temperature, gasification reaction belonged to control area, when the gasification increased $20 \mathrm{~K} \sim 30 \mathrm{~K}$,gasification reaction rate increased nearly one time, so gasification temperature had a decisive influence on thermodynamics and kinetics in gasification process[14].The influence of temperature on the gas composition is shown in Figure 5.The content of $\mathrm{H} 2$ gas was $41.03 \% \sim 44.80 \%$. The content of $\mathrm{CO}$ gas was $23.23 \% \sim 25.09 \%$.The amount of $\mathrm{CH} 4$ gas was $8.71 \% \sim 10.06 \%$.The content of CO2 gas was 9.33\% 9.54\%.

Under the same mass ratio of steam and biomass condition, the volume fraction of $\mathrm{H} 2$ and $\mathrm{CO}$ increased with increase of temperature, while the volume fraction of $\mathrm{CH} 4$ and $\mathrm{CO} 2$ decreased slightly. Changes in individual components of the gas content were the result of a chemical reaction (R1-R9) together. Wherein reaction R6 and R7 are the two main reactions. The increase of temperature made gasification reaction rate speed,,and because the water gas reaction (R6) and hydrocarbon reforming (R9) is an endothermic reaction, so the higher temperature increased the amount of $\mathrm{H} 2$ and $\mathrm{CO}$ quickly. The content of $\mathrm{CH} 4$ is mainly generated by volatile matter of vinegar. As the temperature increases, positive reaction of the methane reforming reaction(R9) speeds, CH4 accelerates the decomposition, which results in the decrease of the content of $\mathrm{CH} 4$. the industrial analysis shows that volatile content and oxygen content of vinegar bad is higher, pyrolysis process will release a certain amount of $\mathrm{CO} 2$, but with increasing temperature, rate of $\mathrm{CO} 2$ and coke reaction(R7)speeds which makes the content of $\mathrm{CO} 2$ has a trace of down. Figure 5 reveals thatthe trend of simulation results and experimental results agree with each other well.

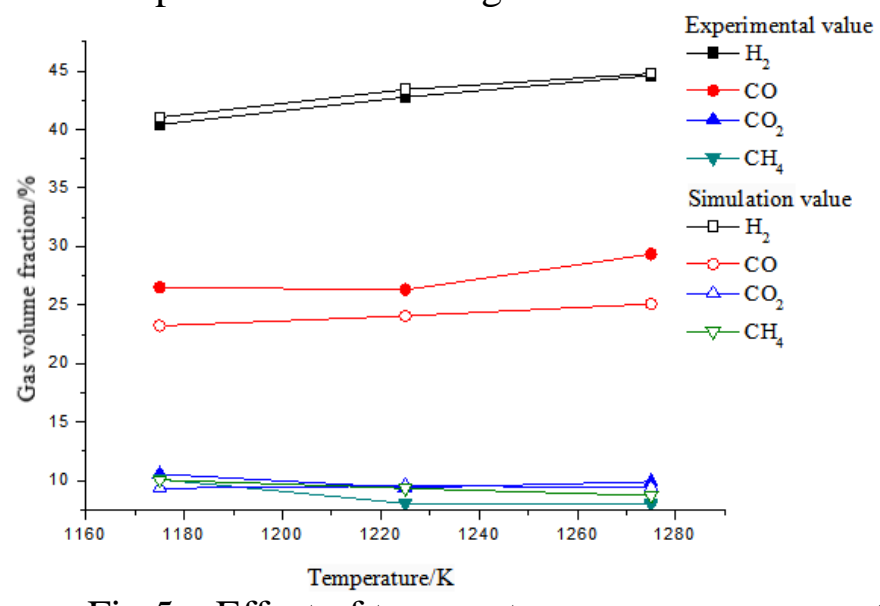

Fig.5 Effect of temperature on gas component

\section{Summary}

The presented study disclosed that, when $\mathrm{mS} / \mathrm{mB}$ increased in the range from 1.23 to 2.47 , the trend of the volume fraction of $\mathrm{H} 2$ increased, however the volume fraction of CO decreased. The content of $(\mathrm{H} 2+\mathrm{CO})$ gas increased. The content of $\mathrm{CH} 4$ gas had trace increace with mass ratio of steam to biomass increasing. When $\mathrm{mS} / \mathrm{mB}$ increased in the range from 2.47 to 3.57 , the volume fraction of gas composition changed slightly since the arrival of saturated steam. The change was gradually stabilized.When temperature increased,the gasification reaction rate speeded,,and because the water gas reaction (R6) and hydrocarbon reforming (R9) was an endothermic reaction, so thehigher temperature increased the amount of $\mathrm{H} 2$ and $\mathrm{CO}$ quickly.The methane reforming reaction(R9) led to the decrease of the content of $\mathrm{CH} 4 . \mathrm{CO} 2$ and coke reaction(R7) made the content of $\mathrm{CO} 2$ has a trace of down.

Coincided basically with the calculated results and experimental results, it shows that the dynamic model can do accurate simulation of fluidized bed gasification. 


\section{References}

[1] Zhongfu Tan,Kangting Chen,Pingkuo Liu. Possibilities and challenges of China's forestry biomass resource utilization. Renewable and Sustainable Energy Reviews, 2015,41:268-378.

[2] Zohreh Ravaghi-Ardebili, Flavio Manenti, Michele Corbetta, Carlo Pirola, Eliseo Ranzi.Biomass gasification using low-temperature solar-driven steam supply.Renewable Energy,2015,74:671-680.

[3] karl M.Broer, Patrick J.Woolcock,Patrick A.Johnston, Robert C.Brown.Steam/oxygen gasification system for the production of clean syngas from switchgrass. Fuel,2015,140:282-292

[4] Hiroaki Watanable, Kenji Tanno, Hiroaki Umetsu, Satoshi Umemoto.Modeling and simulation of coal gasification on an entrained flow coal gasifier with a recycled $\mathrm{CO}_{2}$ injection. Fuel,2015,142:250-259.

[5] Stephen G. Gopaul, Animesh Dutta, Ryan Clemmer. Chemical looping gasification for hydrogen production: A comparison of two unique processes simulated using ASPEN Plus.International Journal of Hydrogen Energy,2014,39:5804-5817.

[6] Scott Cooper, Charles J. Coronella. CFD simulations of particle mixing in a binary fluidized bed. Powder Technology,2005,151(1/3):27-36.

[7] Cao Jun, Zhong Wenqi, Jin Baosheng, etal. Three-dimensional numerical simulation on process of biomass gasification in fluidized bed. Journal of Engineering Thermophysics, 2014,35(6):1114-1118.

[8] Dale M.Snider,Samuel M Clark,Peter J.O'Rourke.Eulerian-Lagrangian method for three-dimensional thermal reacting flow with application to coal gasifiers. Chemical Engineering Science,2011,66(6):1285-1295. 